\title{
Optimization of osmotic dehydration process for Oyster mushrooms (Pleurotus sajor-caju) in sodium chloride solution using RSM
}

\author{
H. G. Ramya ${ }^{1 *}$, Satish Kumar' ${ }^{1}$ and Shammi Kapoor ${ }^{2}$ \\ ${ }^{1}$ Department of Processing and Food Engineering, COAE \&T, PAU, Ludhiana (Punjab), INDIA \\ ${ }^{2}$ Department of Microbiology, COBS \& H, PAU, Ludhiana (Punjab), INDIA \\ *Corresponding author. E-mail: ramyarinda@gmail.com
}

Received: January 10, 2014; Revised received: March 10, 2014; Accepted: April 20, 2014

\begin{abstract}
Sodium chloride $(\mathrm{NaCl})$ and water transfer were quantitatively investigated during osmotic dehydration of Oyster mushrooms (Pleurotus sajor-caju) using response surface methodology with the $\mathrm{NaCl}$ concentration (10$20 \%, \mathrm{w} / \mathrm{v})$, solution temperature $\left(30-60^{\circ} \mathrm{C}\right)$ immersio $\mathrm{n}$ time $(15-240 \mathrm{~min})$ and solution to fruit ratio $(4: 1$ to $8: 1)$ were taken as independent process variables. Experiments were conducted in a thermostatically controlled agitating incubator. For each response, second order polynomial models were developed using multiple linear regression analysis. Analysis of variance (ANOVA) was performed to check the adequacy and accuracy of the fitted models. The response surfaces and contour maps showing the interaction of process variables were constructed. Applying desirability function method, the optimum operating conditions were found to be: solution temperature $-45^{\circ} \mathrm{C}$, immersion time $-53.54 \mathrm{~min}$, salt concentration $-14.09 \%$ and solution to fruit ratio $6.08: 1$. Corresponding to these optimum values water loss, solute gain and weight reduction were 38.13, 2.1 and $36.02(\mathrm{~g} / 100 \mathrm{~g}$ initial mass) respectively.
\end{abstract}

Keywords: Optimization, Osmotic dehydration, Oyster mushrooms, Response surface methodology

\section{INTRODUCTION}

Mushrooms have captivated human beings since ancient times. They are a product of transformation inedible waste into edible biomass, and are generally being accepted as food of high quality. Mushrooms are essentially saprophytes (plants without chlorophyll) which thrive by extracting nutrients from the dead and decaying plant and animal matters. They vary greatly in their colour, texture, shape and properties, bearing different names for different species. Mushrooms have been collected and consumed by people since centuries (Anonymous, 2012). Mushroom production and consumption have grown drastically in last two decades. Total commercial mushroom production worldwide has increased more than 21 times in 35 years from 3,00,000 tonnes in 1965 to about 7.5 million tonnes in 2000. Mushroom cultivation has great scope in China, India and in some of other developing countries (Bao, 2004; Royse, 2001). China has the lion share in the world in mushroom production $(50,08,850$ metric tonnes in 2011 and $26,69,841$ tonnes in 2001) and is followed by United States and Canada ( FAOSTAT, 2012).

Mushrooms have been appraised as sources of dietary nutrients and pharmacologically vital compounds useful in medicine since times immemorial. They are considered to be a source of many different nutraceuticals such as unsaturated fatty acids, phenolic compounds, tocopherols, ascorbic acid and carotenoids. Thus, they are used directly in diet to promote health, taking advantage of the additive and synergistic effects of all the bioactive compounds present (Pereira et al., 2012; Vaz et al., 2010). Pleurotus spp. are commonly known as oyster fungus and are the world's third largest commercially important mushroom species produced and appreciated for their delicious taste, high vitamin, protein, carbohydrate, mineral but low fat content. They are known to degrade large insoluble components of lignocellulosic materials and hence play a significant role in their bioconversion to foods and dietary supplements (Bisaria et al., 1987). Mushrooms are the most priced commodity among vegetables, not because of its nutritive value alone but also for its characteristic aroma and flavour which gives 'Umami' taste. Mushrooms even after harvesting continues to respire, mature and senesce resulting in weight loss, veil opening, browning, wilting and finally leads to the spoilage. So, soon after the harvest, fresh mushrooms need to be properly processed to retard post-harvest deterioration till its consumption. Therefore, osmotic dehydration being promising technology for preservation of vegetables and fruits can be used for post-harvest processing of mushrooms to enhance the mushroom product shelf-life (Zhang et al., 2013).

Osmotic dehydration is one of the energy efficient means of dewatering process that entails the partial removal of water from food items. It works by soaking food in a higher osmotic pressure solution/hypertonic/ concentrated solution such as salts, alcohols, starch solutions and concentrated sugars (Anonymous, 2011). 
Osmotic dehydration induces significant changes in the final dehydrated product such as volume reduction, membrane alteration and membrane separation from the cell wall. It also improves nutritional, sensorial and functional properties of food without changing its integrity (Torrengiani, 1993). Limited efforts have so far been made to process $P$. sajor-caju mushroom into dehydrated product. No attempt has been made to optimize the osmotic process parameters for osmo-cum -microwave dehydrated product of $P$. sajor-caju mushroom. The goal of the present study was to determine the effect of osmotic process parameters viz.solution temperature, salt concentration, duration of osmosis and solution to fruit ratio on water loss, solute gain and weight reduction and to optimize these parameters for developing higher quality finished dehydrated mushroom product.

\section{MATERIALS AND METHODS}

Experimental design and statistical analysis: The Response surface methodology (RSM) was applied to the experimental data using a commercial statistical package, Design-Expert trail version 8.0.7.1 (Statease Inc., Minneapolis, USA). RSM is an empirical statistical modeling technique employed for multiple regression analysis using quantitative data obtained from properly designed experiments to solve multivariate equations simultaneously (Prakash Maran et al., 2013). Box-Behnken Design was used to design the experiments. The process parameters (independent variables) selected for the optimization were immersion time $\left(\beta_{1}\right)$, osmotic solution concentration $\left(\beta_{2}\right)$, osmotic solution temperature $\left(\beta_{3}\right)$ and solution to fruit ratio $\left(\beta_{4}\right)$. The range of each independent variable was; $\beta_{1:} 15-240 \mathrm{~min}, \beta_{2:} 10-20 \%, \beta_{3:} 30-60^{\circ} \mathrm{C}$ and $\beta_{4:} 4: 1-$ $8: 1$. The effects of the variables were studied on water loss (WL), solute gain (SG) and weight reduction (WR) of the slices during osmotic process. The variables were standardized for ease in computation and to reduce their relative effect on the responses. The number of experiments $(\mathrm{N})$ required for the development of Box-Behnken Design is defined as $\mathrm{N}=2 \mathrm{k}$ $(\mathrm{k}-1)+\mathrm{C}_{\mathrm{o}}$ (where $\mathrm{k}$ is number of factors and $\mathrm{C}_{\mathrm{o}}$ is the number of central point). The design included 29 experiments with 5 central points. The following polynomial model was fitted to the data:

$$
\begin{aligned}
\mathbf{Y}= & b_{0}+b_{1} \beta_{1}+b_{2} \beta_{2}+b_{3} \beta_{3}+b_{4} \beta_{4}+b_{12} \beta_{12}+b_{13} \beta_{13}+ \\
& b_{14} \beta_{14}+b_{23} \beta_{23}+b_{24} \beta_{24}+b_{34} \beta_{34}+b_{11} \beta_{1}{ }^{2}+ \\
& b_{22} \beta_{2}{ }^{2}+b_{33} \beta_{3}{ }^{2}+b_{44} \beta_{4}{ }^{2}
\end{aligned}
$$

Where, $b_{n}$ are constant regression coefficients; $Y$ is the response (i.e. WL, SG and WR \%); $\beta_{1}, \beta_{2}, \beta_{3}$ and $\beta_{4}$ are immersion time, salt concentration, temperature and STFR respectively. Statistical significance of the terms in the regression equations was examined. Response surface plots were generated with the same software.

Raw materials: Fully matured oyster mushrooms $(P$. sajor-caju) of commercial grade were procured from Mushroom Research Farm, Punjab Agricultural
University, Ludhiana, India. The average moisture content of the mushrooms was found to be $90.3 \%$ on a wet basis initially. The mushrooms were cut into slices and were pre-treated using anti-microbial agent (Citric acid@40g/l) to avoid enzymatic browning (Brennan and Gormely, 2000). The commercial TATA salt was purchased from a local supermarket and was considered as an osmotic agent for being cheap and easily available.

Experimental procedure: The osmotic dehydration was conducted in $250 \mathrm{ml}$ glass beakers, which was placed in a thermostatically controlled shaking incubator. For each experiment, known weights of mushroom (10 g) was taken in a glass beaker containing calculated volumes of osmotic solution (STFR) of different concentrations and were placed inside a temperature and agitation controlled incubator. At each sampling time 15-240 min, the mushroom slices were taken out and then gently blotted with soft adsorbent paper and weighed and the effect of temperature was investigated. In each of the experiments fresh osmotic solution was used. All the experiments were done in duplicates and the average value was taken for calculations. Agitation was necessary to improve the mass transfer, to maintain uniform concentration, temperature profile and to prevent the formation of a dilute solution film around the samples. For each experiment a constant agitation speed of $150 \mathrm{rpm}$ was maintained. Analysis for each sample was carried out; from which WL, SG and WR data were obtained. Net loss of water and solute gain after osmotic dehydration was calculated using the relationship:

$$
\begin{aligned}
& \mathbf{W L}=\mathrm{WR}+\mathrm{SG} \\
& \mathbf{S G}=\left(\mathrm{m}-\mathrm{m}_{0}\right) / \mathrm{M}_{0} \\
& \mathbf{W R}=\left(\mathrm{M}_{0}-\mathrm{M}\right) / \mathrm{M}_{0}
\end{aligned}
$$

Where, $\mathbf{M}_{0}$ - initial mass of sample $(\mathrm{g}), \mathrm{M}$ - mass of sample after dehydration $(\mathrm{g}), \mathrm{m}_{0}$ - initial mass of the solids in sample $(\mathrm{g}), \mathrm{m}$ - mass of the solids in sample after dehydration $(\mathrm{g})$.

\section{RESULTS AND DISCUSSION}

RSM modeling and effect of process variables on responses: The experiments have found out the optimum combination of process parameters and their effects on WL, SG and WR for the osmotic dehydration of mushrooms as per Box-Behnken Design.

A model 'F-value' denotes 'F-statistic' and is the ratio of treatment mean sum of squares to the error mean sum of squares. Higher F-value represents the significance of the model. Lesser the value of F-value represents least significant/non-significant or more error in the model. F-value and p-value are inter-related.

In present study, from values of variables and sources of the Table 1, it can be noticed that as F-value increases p-value decreases, hence represents more significance. A Model F-value of 9.845, 29.708 and 7.65 for WL, SG and WR respectively implies that the 
Table 1. ANOVA for water loss during osmotic dehydration of Oyster mushroom.

\begin{tabular}{|c|c|c|c|c|}
\hline \multirow[b]{2}{*}{ Source } & \multirow[b]{2}{*}{$\mathbf{R}^{2}$} & \multicolumn{3}{|c|}{ Water loss } \\
\hline & & $\begin{array}{l}\text { Sum of } \\
\text { squares }\end{array}$ & F-val. & p-val. \\
\hline Constant & 38.667 & 381.826 & 9.845 & $<0.0001$ \\
\hline$\beta 1-$ & & & & \\
\hline $\begin{array}{l}\text { Immersion } \\
\text { time }\end{array}$ & 1.724 & 35.677 & 12.879 & 0.003 \\
\hline$\beta 2-$ Salt & 0.800 & 7.681 & 2.773 & 0.118 \\
\hline$\beta 3$-Temp. & 4.803 & 276.779 & 99.915 & $<0.0001$ \\
\hline$\beta 4-S T F R$ & 1.433 & 24.653 & 8.899 & 0.010 \\
\hline$\beta 12$ & 0.448 & 0.802 & 0.290 & 0.599 \\
\hline$\beta 13$ & 1.157 & 5.358 & 1.934 & 0.186 \\
\hline$\beta 14$ & 0.608 & 1.480 & 0.534 & 0.477 \\
\hline$\beta 23$ & -0.471 & 0.888 & 0.321 & 0.580 \\
\hline$\beta 24$ & -0.452 & 0.817 & 0.295 & 0.596 \\
\hline$\beta 34$ & 0.133 & 0.071 & 0.025 & 0.875 \\
\hline$\beta 12$ & -1.189 & 9.175 & 3.312 & 0.090 \\
\hline$\beta 22$ & -1.139 & 8.416 & 3.038 & 0.103 \\
\hline$\beta 32$ & -1.623 & 17.090 & 6.169 & 0.026 \\
\hline$\beta 42$ & -1.074 & 7.486 & 2.703 & 0.122 \\
\hline Lack of Fit & & 5.785 & & \\
\hline $\mathrm{R}^{2}$ & & 0.908 & & \\
\hline Adj. $R^{2}$ & & 0.816 & & \\
\hline Pred. $\mathrm{R}^{2}$ & & 0.798 & & \\
\hline CV (\%) & & 4.549 & & \\
\hline Std.Dev & & 1.664 & & \\
\hline $\begin{array}{l}\text { Adeq } \\
\text { Precision }\end{array}$ & & 11.452 & & \\
\hline
\end{tabular}

model is significant $(\mathrm{P}<0.01)$. The 'lack of Fit F-value' of 5.785, 0.404 and 3.903 for WL, SG and WR were not significant which indicates that the model was adequate for predicting the response. Moreover, the predicted $\mathrm{R}^{2}$ values for $\mathrm{WL}, \mathrm{SG}$ and WR of $0.798,0.845$ and 0.762 were in reasonable agreement with adjusted $\mathrm{R}^{2}$ of $0.816,0.935$ and 0.769 . The independent process parameters $\beta_{1}, \beta_{2}, \beta_{3}$ and $\beta_{4}$ were optimized for maximum water loss and minimum solute gain. An analysis of variance was conducted to determine the significant effects of process variables on each response. Tables 1, 2 and 3 showed that all the process variables were found to be statistically significant for WL, SG and WR at ( $\mathrm{p}<0.05)$. Coefficient of determination $R^{2}$ and adj- $R^{2}$ were calculated to check the adequacy and fitness of the model. The values of $\mathrm{R}^{2}$ were calculated to be $0.908,0.967$ and 0.884 for WL, SG and WR respectively which signified the compatibility of the experimental data. The $\mathrm{R}^{2}$ value was always between 0 and 1 , and a value > 0.75 indicated aptness of the model. For a good statistical model, $\mathrm{R}^{2}$ value should be close to 1.0 . The adjusted $\mathrm{R}^{2}$ value corrected the $\mathrm{R}^{2}$ value for the sample size and for the number of terms in the model. These higher values of $\mathrm{R}^{2}$ also signified the high significance of the model. If there are many terms in the model and the sample size is not very large, the adjusted $R^{2}$ may be noticeably smaller than the $\mathrm{R}^{2}$. Here in this case
Table 2. ANOVA for solute gain during osmotic dehydration of Oyster mushroom.

\begin{tabular}{|c|c|c|c|c|}
\hline \multirow[b]{2}{*}{ Source } & \multirow[b]{2}{*}{$\mathbf{R}^{2}$} & \multicolumn{3}{|c|}{ Solute gain } \\
\hline & & $\begin{array}{l}\text { Sum of } \\
\text { squares }\end{array}$ & F-val. & p-val. \\
\hline $\begin{array}{l}\text { Constant } \\
\beta 1-\end{array}$ & 2.237 & 15.720 & 29.708 & $<0.0001$ \\
\hline $\begin{array}{l}\text { Immer- } \\
\text { sion time }\end{array}$ & 0.467 & 2.613 & 69.131 & $<0.0001$ \\
\hline$\beta 2-$ Salt & 0.216 & 0.558 & 14.770 & 0.002 \\
\hline $\begin{array}{l}\beta 3- \\
\text { Temp. }\end{array}$ & 0.870 & 9.073 & 240.051 & $<0.0001$ \\
\hline$\beta 4-S T F R$ & 0.284 & 0.966 & 25.555 & 0.0001 \\
\hline$\beta 12$ & 0.018 & 0.001 & 0.033 & 0.858 \\
\hline$\beta 13$ & 0.163 & 0.106 & 2.809 & 0.116 \\
\hline$\beta 14$ & -0.063 & 0.016 & 0.419 & 0.528 \\
\hline$\beta 23$ & -0.081 & 0.027 & 0.702 & 0.416 \\
\hline$\beta 24$ & 0.098 & 0.039 & 1.020 & 0.330 \\
\hline$\beta 34$ & -0.019 & 0.001 & 0.038 & 0.848 \\
\hline$\beta 12$ & -0.035 & 0.008 & 0.208 & 0.656 \\
\hline$\beta 22$ & -0.067 & 0.029 & 0.765 & 0.396 \\
\hline$\beta 32$ & -0.577 & 2.156 & 57.041 & $<0.0001$ \\
\hline$\beta 42$ & 0.038 & 0.009 & 0.247 & 0.627 \\
\hline $\begin{array}{l}\text { Lack of } \\
\text { Fit }\end{array}$ & & 0.404 & & \\
\hline $\mathrm{R}^{2}$ & & 0.967 & & \\
\hline Adj. $R^{2}$ & & 0.935 & & \\
\hline Pred. $\mathrm{R}^{2}$ & & 0.845 & & \\
\hline CV (\%) & & 9.860 & & \\
\hline Std.Dev & & 0.194 & & \\
\hline $\begin{array}{l}\text { Adeq } \\
\text { Precision }\end{array}$ & & 19.294 & & \\
\hline
\end{tabular}

also it can be noticed adjusted $\mathrm{R}^{2}$ value were lesser than the $R^{2}$. The closer values of $R^{2}$ and adj. $R^{2}$ obtained in the study explicated that the predicted values are in good agreement with the experimental values. Higher values of coefficient of determination obtained for response variables indicated that the developed model for WL, SG and WR accounted for and adequately explained $79.8,84.5$ and $76.2 \%$ of the total variation.

The coefficient of variation (CV \%) indicated the relative dispersion of the experimental points from the predictions of the second-order polynomial models (Prakash Maran et al., 2013). The values of CV are low as 4.549, 9.860 and 4.440 for WL, SG and WR, which indicated that the deviations between experimental and predicted values are low. The values of Adeq Precision are 11.452, 19.294 and 10.019 for WL, SG and WR. Adeq Precision measures the signal to noise ratio. A ratio greater than 4 is desirable. In this work the ratio is found to be $>10$, which indicates an adequate signal. The comparative effect of each factor on WL, SG and WR were observed by the F-values in the ANOVA (Tables 1-3) and also by the magnitudes of coefficients of the coded variables. The F-values indicated that solution temperature and immersion time were the most influencing factors followed by STFR and salt concentration was least effective over WL, SG and WR.

The effect of $\beta_{1}, \beta_{2}, \beta_{3}$ and $\beta_{4}$ on the WL is given in fig.1. The WL increased rapidly in the early stages of 


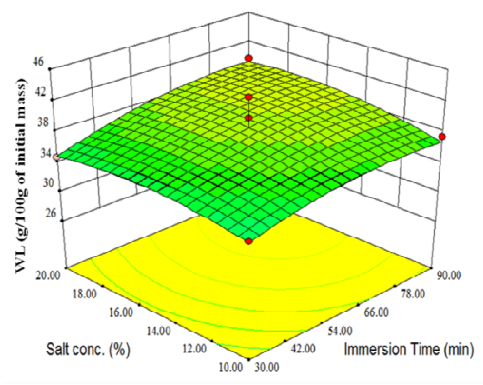

(a)

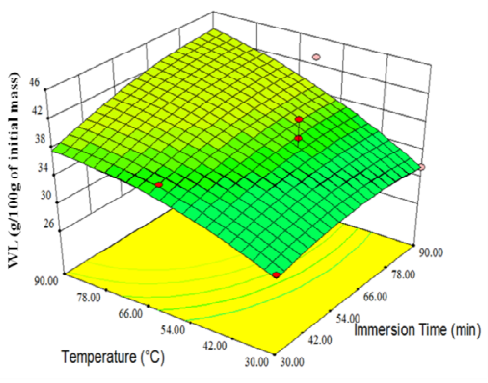

(b)

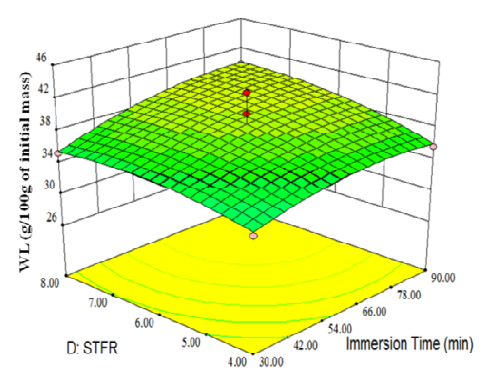

(c)

Fig. 1. Water loss during osmotic dehydration of mushroom as a function of : (a) salt concentration and immersion time (b) solution temperature and immersion time (c) STFR and immersion time.

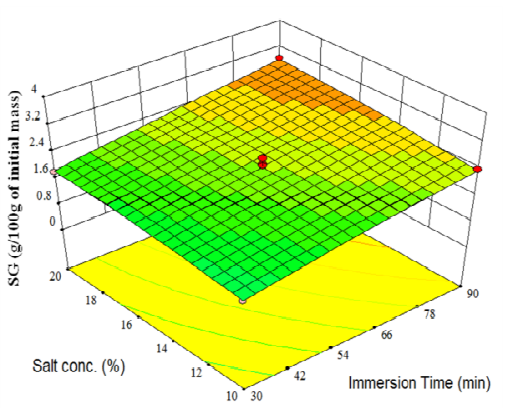

(a)

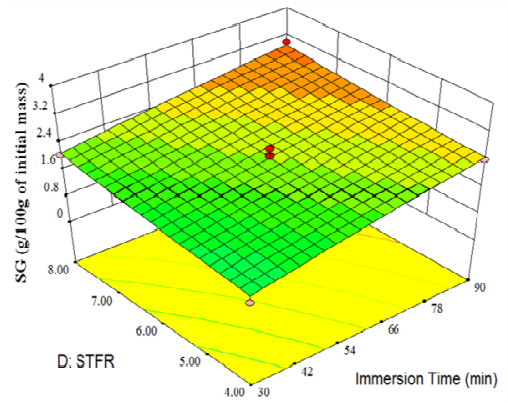

(b)

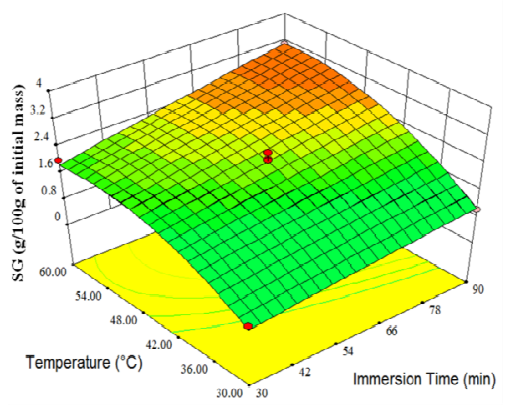

(c)

Fig. 2. Solute Gain during osmotic dehydration of mushroom as a function of : (a) salt concentration and immersion time (b) solution temperature and immersion time (c) STFR and immersion time.

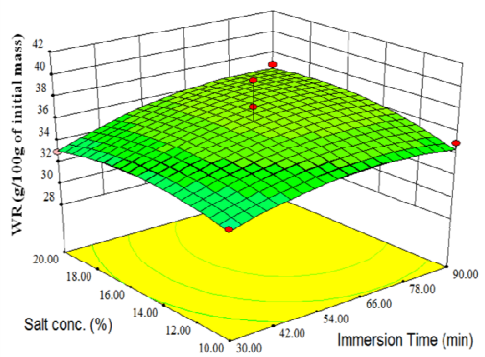

(a)

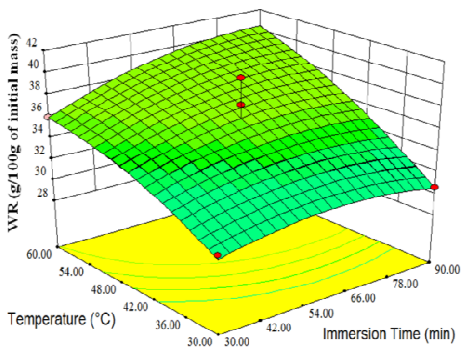

(b)

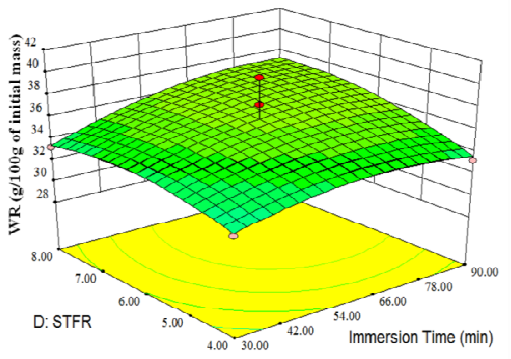

(c)

Fig. 3. Weight reduction (WR) during osmotic dehydration of mushroom as a function of : (a) salt concentration and immersion time (b) solution temperature and immersion time (c) STFR and immersion time.

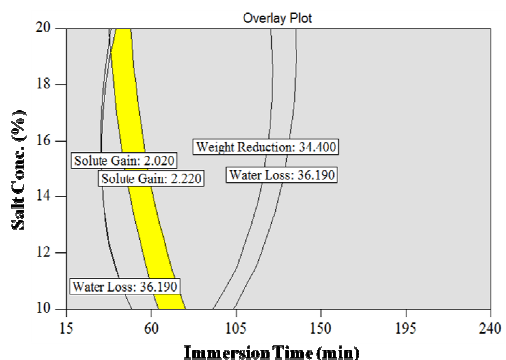

(a)

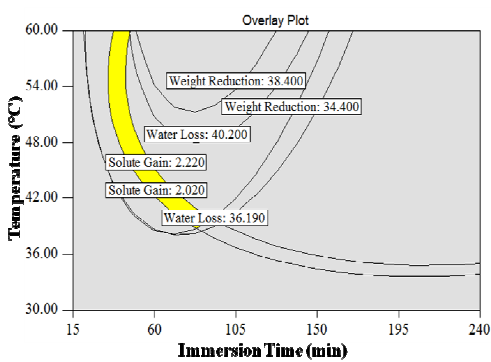

(b)

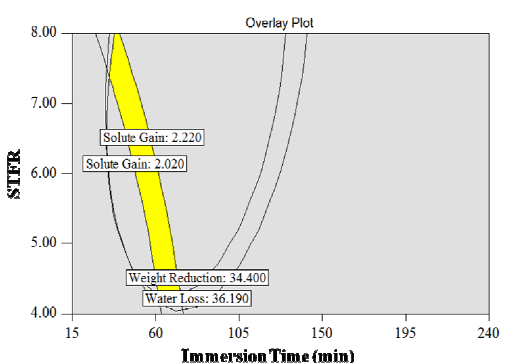

(c)

Fig. 4. Superimposed contour plots of different responses for optimization of osmotic dehydration of mushroom as function of (a) salt concentration and immersion time (b) solution temperature and immersion time (c) STFR and immersion time. 
Table 3. ANOVA for weight reduction during osmotic dehydration of Oyster mushroom.

\begin{tabular}{lllll}
\hline & \multirow{4}{c}{ Weight reduction } \\
\cline { 3 - 5 } Source & $\mathbf{R}^{\mathbf{2}}$ & $\begin{array}{l}\text { Sum of } \\
\text { squares }\end{array}$ & F-val. & p-val. \\
\hline Constant & 36.430 & 252.925 & 7.650 & $<0.0003$ \\
$\beta 1$ - & & & & \\
Immersion & 1.258 & 18.980 & 8.037 & 0.013 \\
time & & & & \\
$\beta 2-$ Salt & 0.584 & 4.098 & 1.735 & 0.209 \\
$\beta 3$-Temp. & 3.933 & 185.628 & 78.601 & $<0.0001$ \\
$\beta 4-$ STR & 1.150 & 15.859 & 6.715 & 0.021 \\
$\beta 12$ & 0.430 & 0.740 & 0.313 & 0.584 \\
$\beta 13$ & 0.994 & 3.956 & 1.675 & 0.217 \\
$\beta 14$ & 0.671 & 1.803 & 0.763 & 0.397 \\
$\beta 23$ & -0.390 & 0.608 & 0.257 & 0.620 \\
$\beta 24$ & -0.550 & 1.210 & 0.512 & 0.486 \\
$\beta 34$ & 0.152 & 0.092 & 0.039 & 0.846 \\
$\beta 12$ & -1.155 & 8.646 & 3.661 & 0.076 \\
$\beta 22$ & -1.072 & 7.459 & 3.158 & 0.097 \\
$\beta 32$ & -1.047 & 7.106 & 3.009 & 0.105 \\
$\beta 42$ & -1.112 & 8.025 & 3.398 & 0.087 \\
Lack of Fit & & 3.903 & & \\
$\mathrm{R}^{2}$ & & 0.884 & & \\
Adj. R ${ }^{2}$ & & 0.769 & & \\
Pred. R & & 0.762 & & \\
CV $(\%)$ & & 4.440 & & \\
Std.Dev & & 1.537 & & \\
Adeq & & 10.019 & & \\
Precision & & & \\
\hline
\end{tabular}

the immersion, after which the rate of water loss from mushrooms into the solution gradually slowed down with time towards equilibrium end point. On the other hand, the WL increased gradually with salt concentration over the entire osmotic dehydration process. WL increased with temperature especially in the early stages of the immersion. Higher temperatures seem to promote faster water loss through swelling and plasticising of cell membranes as well as the better water transfer characteristics on the product surface due to lower viscosity of the osmotic medium (Contreras and Smyral, 1981). Rapid removal of water in early stages with increasing temperatures of osmosis has been reported for mushrooms (Kar and Gupta, 2001; Murumkar et al., 2007), green pumpkins (Chang et al., 2003), potatoes (Eren and Kaymak-Ertekin, 2006), litchi (Vishal et al., 2009) and papaya (Jain et al., 2011).

So, initial stages of osmotic dehydration is the most important one, since the transport phenomena are faster and they have a dramatic impact on further evolution of the osmotic process (Biswal et al., 1991; Conway et al., 1983; Hawkes and Flink, 1978). The effect of $\beta_{1}, \beta_{2}, \beta_{3}$ and $\beta_{4}$ on the SG is given in fig. 2 . The $S G$ increases sharply with immersion time and temperature. The effect of $\beta_{1}, \beta_{2}, \beta_{3}$ and $\beta_{4}$ on the WR is given in fig.3. WR mainly depends upon WL and SG during osmotic dehydration process.

The experimental results are analyzed through RSM to obtain in empirical model for the best response. The mathematical expressions of relationship describing the effects of process variables to the response are shown below.

$$
\begin{aligned}
\mathbf{W L}= & 38.67+1.72 \beta_{1}+0.80 \beta_{2}+4.80 \beta_{3}+1.43 \beta_{4}+0.45 \\
& \beta_{12}+1.16 \beta_{13}+0.61 \beta_{14}-0.47 \beta_{23}-0.45 \beta_{24}+0.13 \\
& \beta_{34}-1.19 \beta_{1}{ }^{2}-1.14 \beta_{2}{ }^{2}-1.62 \beta_{3}{ }^{2}-1.07 \beta_{4}{ }^{2} \\
\mathbf{S G}= & 2.24+0.47 \beta_{1}+0.22 \beta_{2}+0.87 \beta_{3}+0.28 \beta_{4}+0.018 \\
& \beta_{12}+0.16 \beta_{13}-0.063 \beta_{14}-0.081 \beta_{23}+0.098 \\
& \beta_{24}-0.019 \beta_{34}-0.035 \beta_{1}{ }^{2}-0.067 \beta_{2}{ }^{2}-0.58 \\
& \beta_{3}{ }^{2}+0.038 \beta_{4}{ }^{2} \\
\mathbf{W R}= & 36.43+1.26 \beta_{1}+0.58 \beta_{2}+3.93 \beta_{3}+1.15 \beta_{4}+0.43 \\
& \beta_{12}+0.99 \beta_{13}+0.67 \beta_{14}-0.39 \beta_{23}-0.55 \beta_{24}+0.15 \\
& \beta_{34}-1.15 \beta_{1}{ }^{2}-1.07 \beta_{2}{ }^{2}-1.05 \beta_{3}{ }^{2}-1.11 \beta_{4}{ }^{2}
\end{aligned}
$$

Where, WL, SG, WR are water loss $(\%)$, solute gain (\%) and weight reduction (\%) respectively, and $\beta_{1}, \beta_{2}$, $\beta_{3}$ and $\beta_{4}$ are the coded values of the test variables, immersion time $(\mathrm{min})$, salt concentration $(\%)$, solution temperature $\left({ }^{\circ} \mathrm{C}\right)$ and solution to fruit ratio respectively, as mentioned earlier.

The presence of positive interaction terms between $\beta_{1}$,

\begin{tabular}{|c|c|c|c|c|c|}
\hline Process parameters & Goal & $\begin{array}{l}\text { Experimental } \\
\text { range }\end{array}$ & Importance & $\begin{array}{l}\text { Optimum } \\
\text { values }\end{array}$ & Desirability \\
\hline Time (min) & is in range & $30-90$ & 3 & 53.54 & \\
\hline Salt $(\%)$ & is in range & $10-20$ & 3 & 14.09 & \\
\hline Temp $\left({ }^{\circ} \mathrm{C}\right)$ & target & 45 & 3 & 45.00 & \\
\hline STFR & is in range & $4: 1-8: 1$ & 3 & $6.08: 1$ & \\
\hline Responses & & & & $\begin{array}{l}\text { Predicted } \\
\text { values }\end{array}$ & 0.626 \\
\hline WL (g/100g of initial mass) & maximize & $29.19-43.19$ & 3 & 38.1298 & \\
\hline $\mathrm{SG}$ (g/100g of initial mass) & minimize & $0.448-3.10$ & 3 & 2.1053 & \\
\hline WR ( $\mathrm{g} / 100 \mathrm{~g}$ of initial mass) & maximize & $28.744-40.09$ & 3 & 36.0246 & \\
\hline
\end{tabular}
$\beta_{2}, \beta_{3}$ and $\beta_{4}$ indicated that increase in their levels increased WL, SG and WR. The negative values of quadratic terms of process variables of osmosis indicated that higher values of these variables further reduced WL, SG and WR. The analysis of variance of quadratic regression model demonstrated that equation (5), (6) and (7) were highly significant models, as were

Table 4. Range of process parameters and their importance for optimization of osmotic dehydration and solution generated through the RSM Technique in salt solution. 
evident from F-test with very low probability value ( $p$ model $=<0.0001,<0.0001$ and 0.0003 ) for WL, SG and WR respectively. This indicates that the linear terms of $\beta_{1}, \beta_{2}, \beta_{3}$ and $\beta_{4}$ of osmosis were highly significant at 5 per cent level.

Response surface and contour plots: Response surface plots as a function of two factors at a time, maintaining all other factors at fixed levels are more helpful in

understanding both the main and the interactive effects of these two factors. The response surface curves were plotted to understand the interaction of the variables and to determine the optimum level of each variable for maximum response. The 3D surface and contour plots for WL, SG and WR along with overlay plots are shown in Fig. 1-4 respectively. Figures show the effects of process variables such as $\beta_{1}, \beta_{2}, \beta_{3}$ and $\beta_{4}$ on WL, SG and WR during the osmotic dehydration of oyster mushrooms. The higher processing temperature and immersion time promote rapid water loss ad solute uptake along with increased STFR and salt concentration.

Temperature has an effect on the cell membrane permeability that could allow solute to enter by losing its selectivity. Decrease of solution viscosity at higher temperature may influence salt gain due to fact that lower viscosity decreases the resistance to diffusion of solutes into the sample tissue. Increased concentration of the salt solution also led to increase in salt gain. This is probably due to an increase of osmotic pressure gradient and consequent loss of functionality of cell plasmatic membrane that allows solute to enter. Rapid loss of water and uptake of solute near the surface in the beginning may result in structural changes leading to crust formation/compaction of surface layers and which results in increased mass transfer resistance for water and solutes (Alam et al., 2010). During osmotic dehydration, water removal from the product is always accompanied by the simultaneous counter diffusion of solutes from the osmotic solution into the tissue. In most common operating conditions, mass transfer mainly occurs during the first $2 \mathrm{~h}$ for water loss and first $50 \mathrm{~min}$ for solute gains (Rault et al., 1989). Further, studies also confessed that moisture loss occurs in the first hour of the osmotic process (Rezagah et al., 2010). The mass transfer rates thus become progressively lower with time and water loss stops, whereas solute gain goes on increasing regularly (Ertekin and Çakaloz, 1995). Rapid removal of water in the early stages of osmotic dehydration has been reported by several authors (Ertekin and Çakaloz, 1996; Lazarides et al., 1995; Shi and Le Maguer, 2002).

Optimization of osmotic dehydration of mushroom: Design-Expert trail version 8.0.7.1 (Statease Inc., Minneapolis, USA) was used for getting optimal values for multiple responses, as discussed in section 2.1. Graphical multi-response optimization technique was adopted to determine the workable optimum conditions for the osmotic dehydration of oyster mushrooms. The contour plots for all the responses were superimposed and regions that best satisfy all the constraints were selected as optimum conditions. The main criteria for constraints optimization were maximum possible water loss, weight reduction and minimum solute gain. These constraints resulted in feasible zone (yellow coloured area in the superimposed contour plots) of the optimum conditions. Superimposed contour plots having common superimposed area of all the responses for osmotic dehydration in sodium chloride solution are presented from Figs. 1-4. These above results clearly indicate the suitability of the developed models. The optimum ranges of process parameters obtained for osmotic dehydration of oyster mushrooms were: 30 -90 min immersion time; $10-20 \%$ salt concentration; $45^{\circ} \mathrm{C}$ and 4:1-8:1 solution to fruit ratio. Numerical multi response technique was carried out for optimization of process. Equal importance of ' 3 ' was given to all the four parameters. The constraints were set such that the selected variables would be minimum from economical point of view for the most important product attribute. Goal of the present study was to maximize the water loss and weight reduction values as high as possible and to minimize solute as low as possible.

The optimum conditions were found to be $\beta_{1}=53.54$ $\min , \beta_{2}=14.09 \%, \beta_{3}=45^{\circ} \mathrm{C}$ and $\beta_{4}=6.08: 1$. At these optimum conditions, WL, SG and WR were found to be $38.13,2.10$ and 36.02 ( $\mathrm{g} / 100 \mathrm{~g}$ of initial mass) with overall desirability value of 0.626 . Table 4 . shows the software generated optimum conditions i.e. range of process parameters and their importance for optimization of osmotic dehydration and solution generated through the RSM Technique in sodium chloride salt solution.

\section{Conclusion}

It was concluded that RSM generated optimum operating conditions yielded maximum water loss and weight reduction and minimum solute gain in osmotic dehydration of Oyster mushroom. Analysis of variance has shown that the effects of all the process variables including solution temperature, immersion time, salt concentration and solution to fruit ratio were statistically significant. Second order polynomial models were obtained for predicting water loss, solute gain and weight reduction. The optimum conditions were found to be: solution temperature $-45^{\circ} \mathrm{C}$, immersion time - $53.54 \mathrm{~min}$, salt concentration $-14.09 \%$ and solution to fruit ratio 6.08:1. At these optimum values, water loss, solute gain and weight reduction were found to be 38.13 (g/100 g initial mass), 2.1 (g/100 g initial mass) and 36.02 (g/100 g initial mass) respectively.

\section{ACKNOWLEDGEMENT}

The author would wish to thank "The Ministry of Science and Technology, Department of Science and Technology (DST), GOI" for providing financial 
support during the course of Research Studies.

\section{REFERENCES}

Alam, M. S., Singh, A. and Sawhney, B. K. (2010). Response surface optimization of osmotic dehydration process for Anola slices. Food Science and Technology, 47: 47- 54.

Anonymous Health Benefits of Mushroom. (2012). (http:// www.organicfacts.net/health-benefits/vegetable/healthbenefits-of-mushroom.html\#.UGz0MpjMhD0). (Accessed on $5^{\text {th }}$ August 2012).

Anonymous (2011). What is osmotic dehydration? eHow.com http://www.ehow.com/about_4651875_what -osmotic-dehydration.html\#ixzz2P7m7U9kn). (Accessed on $6^{\text {th }}$ October 2011).

Bao, E. (2004). Wild edible fungi a global overview of their use and importance to people. FAO, Rome. pp. 148.

Bisaria, R., Madan, M. and Bisaria, V. S. (1987). Biological efficiency and nutritive value of Pleurotus sajor-caju cultivated on different agro-wastes. Biological Wastes, 19: 239- 255.

Biswal, R. N., Bozorgmehr, K., Tompkins, F. D. and Liu, X. (1991). Osmotic concentration of green beans prior to freezing. Journal of Food Science, 56:1008- 1012.

Brennan, M. H. and Gormely. (2000) Extending the shelf life of fresh sliced mushrooms. Journal of the Science of Food and Agriculture, 26: 401-411.

Chang, M. J., Han, M. R., Kim, M. H. (2003). Effects of salt addition in sugar based osmotic dehydration on mass transfer and browning reaction of green Pumpkin. Agriculyural Chemistry and Biotechnology, 46: 92- 96.

Contreras, J. E. and Smyral, T. G. (1981). An evaluation of osmotic concentration of apple rings using corn syrup solids solutions. Canadian Institute of Food Science and Technology Journal, 14: 310- 314.

Conway, J., Castaigne, F., Picard, G. and Vovan, X. (1983). Mass transfer considerations in the osmotic dehydration of apples. Canadian Institute of Food Science Technology Journal, 16: 25- 29.

Eren, I. and Kaymak-Ertekin, F. (2006). Optimization of Osmotic dehydration of potato using response surface methodology. Journal of Food Engineering, 79:344352.

Ertekin, F. K. and Çakaloz, T. (1995). Osmotic dehydration of peas: II. Influence of osmosis on drying behaviour and product quality. Journal of Food Processing and Preservation, 20: 105- 119.

Ertekin, F. K. and Çakaloz, T. (1996). Osmotic dehydration of peas: I. Influence of process variables on mass transfer. Journal of Food Processing and Preservation, 20:87- 104

FAOSTAT (2012). Food and agriculture organization of the United Nations. (http://faostat.fao.org/site/339/ default.aspx). (Accessed on $15^{\text {th }}$ December 2012).

Hawkes, J. and Flink, J. M. (1978). Osmotic concentration of fruit slices prior to freeze dehydration. Journal of
Food Processing and Preservation, 2:265- 284.

Jain, S. K., Verma, R. C., Murdia, L. K., Jain, H. K. and Sharma, G. P. (2011). Optimization of process parameters for Osmotic dehydration of Papaya cubes. Food Science and Technology, 48: 211-217.

Kar, A. and Gupta, D. K. (2001). Osmotic dehydration characteristics of button mushroom. Food Science and Technology, 40: 23- 27.

Lazarides, H. N., Katsanidis, E. and Nickolaidis, A. (1995). Mass transfer kinetics during osmotic preconcentration aiming at minimal solid uptake. Journal of Food Engineering, 25: 151-166.

Murumkar, R. P., Jain, S. K., Pilaskar, P. S. and Verma, R. C. (2007). Osmo-fluid bed drying of white button mushroom. Bioved-An International Bi-Annual Journal of Life Science, 18: 47- 52.

Pereira, E., Barros, L., Martins, A. and Ferreira, I.C.F.R. (2012). Towards chemical and nutritional inventory of Portuguese wild edible mushrooms in different habitats. Food Chemistry, 130: 394- 403.

Prakash Maran, J.P., Manikandan, S., Thirugnanasambandham, K., Vigna Nivetha, C. and Dinesh, R. (2013) Box-Behnken design based statistical modeling for ultrasoundassisted extraction of corn silk polysaccharide. Carbohydrate Polymers, 92: 604- 611.

Rault, A. L., Lafont, F., Rios, G. and Guilbert, S. (1989). Osmotic dehydration: study of mass transfer in terms of engineering properties. In A. S. Majumdar and M. Roques (Eds.), Drying. NY: Hemisphere Publishing House. 89: 487- 495.

Rezagah, M. E., Kashaninejad, M., Mirzaei, H. and Khomeiri, M. (2010). Osmotic dehydration of button mushroom: Fickian diffusion in slab configuration. Latin American Applied Research, 40: 23-26.

Royse, D. J. (2001). Cultivation of shiitake on natural and synthetic logs. Penn State's College of Agricultural Science. Available at: (http://www.cas.psu.edu/Free Pubs/pdfs/ul203.pdf).

Shi, J. and Le, Maguer, M. (2002). Osmotic dehydration of foods: mass transfer and modeling aspects. Food Reviews international, 18: 305- 335.

Torrengiani, D. (1993). Osmotic dehydration in fruits and vegetable processing. Food Research International, 26: 59- 68.

Vaz, J. A., Heleno, S. A., Martins, A., Almeida, G. M., Vasconcelos, M. H. and Ferreira, I. C. F. R. (2010). Wild mushrooms Clitocybe alexandri and Lepista inversa: in vitro antioxidant activity and growth inhibition of human tumour cell lines. Food and Chemistry Toxicology, 48: 2881- 2884.

Vishal, K., Gunjan, K. and Sharma, P. D. (2009). Effect of Osmo-convective drying on quality of Litchi. Agricultural Engineering, 46: 31- 35.

Zhang, Y, Venkitasamy, C., Pan, Z. and Wang, W. (2013). Recent developments on umami ingredients of edible mushrooms - A review. Trends in Food Science and Technology, 33: 78-92. 